$\ldots$ the intertidal and

the open ocean are

both parts of a unified

whole... expedition. The deep sea is presented as a habitat that is quiescent, cold and dark, where food limitation is perhaps the primary constraint on life. Our present day concepts about the deep sea include a more dynamic, variable environment in which the seabed and its creatures are actively involved in geochemical processes and exchange between the seabed and the water column. Observations and experiments have revealed an active deep-sea fauna that ranges over large distances. The well known discoveries of hydrothermal vents, and their specialized fauna and food web based on chemosynthesis, have altered old concepts dramatically over the past decade or two.

Additionally, The Oceans contains numerous examples and discussion of the fauna of the intertidal zone and the specialized demands of that habitat. Perhaps because of its accessibility, research in the intertidal zone has been active for a reasonably long time, and many observations of earlier decades remain relevant today. Inclusion of the whole range of marine habitats in The Oceans, and the point of view that the intertidal and the open ocean are both parts of a unified whole, is one of the strengths of the text. Present day thinking about marine habitats has become highly specialized and fragmented. The attempt to present a synthesis including many habitats not only informs the reader of the variety of biological problems available for study (and most of these continue to confront us) but also demands that we step back and consider a broader context for our oceanographic investigations.

Among the most stimulating and presently valid sections of the book are the discussions of production, food-web structure, and the effects of the ocean's physical forces on populations and communities. For example, consider the description of the attributes of halibut eggs and larvae, the life cycle of the adult fish, and the currents of their Alaskan habitat found in The Oceans. It is substantially what has become known today as fisheries oceanography. And in a discussion of temperate production cycles that predates much of Gordon Riley's work, The Oceans emphasizes the importance of annual cycles in production and consumption of organic material and the need to compare rates of these properties in analyzing ecosystems. It seems as if in the intervening 50 years, we have succeeded only in gathering snapshots of oceanic ecosystems, many of which support The Oceans' description of pelagic processes. We have not made as many remarkable advances in our understanding as we would like to think we have. The Oceans emphasizes the interactions and influences of many aspects of the oceanic environment on its biological populations and processes. This defines interdisciplinary research, the focus of many ongoing and planned research programs.

\title{
The OCEANS: The Geological Bookends
}

By Dean A. McManus

$T$ L HE OCEANS Opens with a discussion of bottom topography and closes with a discussion of sediments. These chapters are not so much introduction and summary, however, as sturdy bookends to hold the Physics, Chemistry, and General Bi$o \log y$, of the book's subtitle. In fact, the last chapter seems to have been an afterthought, inasmuch as it was penned into the original typed list of chapters (SIO Archives Collection 81-123, v. 1, p. 8).

These two geological chapters appear to have been chiefly written by chemical oceanographer

D.A. McManus, School of Oceanography, University of Washington, Seattle, WA 98195, USA.
Richard Fleming. They are of value mainly for the sense of completeness they provide the book. As a contribution to geology, they suffer from the poor timing of their publication. Only a scant three years earlier, geologists had been blessed with that hefty classic Recent Marine Sediments, edited by Parker Trask, which is almost three-quarters the length of the bulky Oceans. Trask's book was widely used in geology departments and was even reprinted 16 years later. Nevertheless, I'm told that the two chapters from The Oceans were used by Fran Shepard in teaching his submarine geology course at Scripps during the 1940s.

Then in 1948 Shepard's own book, Submarine Geology, was published, to be followed two years 


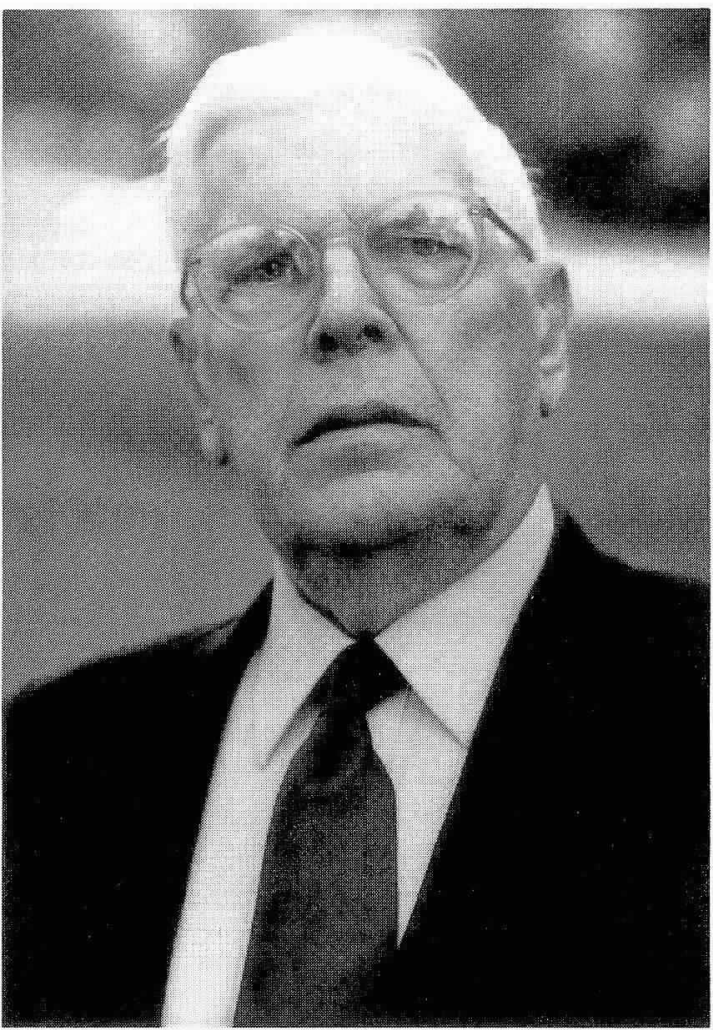

Richard H. Fleming

later by Phil Kuenen's Marine Geology. One or the other of these books became the standard in oceanographic institutions and geology departments throughout the 1950 s. Thus The Oceans was immediately preceded by a sedimentation classic and followed, soon after the war, by two texts devoted wholly to marine geology. All the same, the two chapters are important for their global perspective. Not that this was original. After all, John Murray produced global charts of topography and sediment distribution for the Challenger Reports. But the chart on page 975 of The Oceans showing pelagic sediment distribution in the world ocean, albeit an updated version of Murray's chart, was subsequently used by both Shepard and Kuenen and, in fact, became the new standard.

The chapter on bottom topography is a geography lesson-appropriate when we recall that the echo sounder was still new at that time. Until one looks at Figure 1 in that chapter, it is difficult to appreciate the number and variety of new bottom features that echo sounding was discovering for description and classification. Even so, Fleming's approach to the topic was clearly that of a watercolumn oceanographer, not a marine geophysicist: "From the oceanographic point of view," he writes, "the chief interest in the topography of the sea floor is that it forms the lower and lateral boundaries of water" (p. 14). No curiosity about crustal structure or permanence of ocean basins there! Only passing reference is made to the pioneering efforts in marine geophysics that were being nurtured on the East Coast by Dick Field and William Bowie. For Fleming and for The Oceans, the topography was important only for its effect on deep-water circulation. Even the geologically "hot" topics of the day such as the origin of continental shelves, origin of submarine canyons, and classification of shorelines did not fare well. But then, Sverdrup, himself, had written that ". . . details of the submarine topography are of small interest and the geological character of the rocks forming the bottom is insignificant" (Shor, 1978 , p. 271). So there!

Much of the material in both chapters is badly dated now, as we would expect. The sediment chapter, remember, was written before the significance of Kuenen's first turbidity current experiments was recognized, when $\mathrm{X}$-ray classification of clay minerals was but a few years old, and before the first extensive rock-dredging of midocean ridges took place. Nevertheless, Fleming presents some acute perceptions.

Calcium carbonate in pelagic sediments is discussed more in terms of the supply of carbonate particles, rather than dissolution, as controlling the distribution of carbonate sediments (the calcite compensation depth was not yet a concept). Nevertheless, on page 1001 the rate conditions of supply and dissolution are stated, and these would come to define the CCD. The data were just not sufficient to go further at that time.

Another perceptive section is the discussion of sediment transport in the benthic boundary layer. Here, Fleming expands upon what he and Roger Revelle wrote for their chapter in Recent Marine Sediments, and he adds other information from that book: Stokes's equation of settling velocity, the von Karman-Prandtl velocity profile equation, Hjulstrom's diagram. Such an introduction to sediment transport would not appear in sedimentation texts until the 1970 s-30 years later!

There was little that Fleming could say about the geologic history of marine sediments. He remarks upon a recent technological advance that had obtained cores up to $3 \mathrm{~m}$ in length. This had "opened a new field." Not only were cores short, but dating and estimates of accumulation rates were by indirect stratigraphic methods. Still, those methods did give rates for deep-sea sediments of $<1 \mathrm{~cm} / 1,000$ years. And here Fleming cites $\mathrm{Ku}-$ enen and others in one of the all-time pregnant remarks: those rates mean that "it is difficult to account for the supply of the tremendous mass of material, which must have accumulated in the deep sea since the beginning of geological time" (p. 1036). It would take another quarter century before that remark gave birth to geologic understanding.
... the two chapters

(addressing marine

geology) are important

for their global

perspective. 


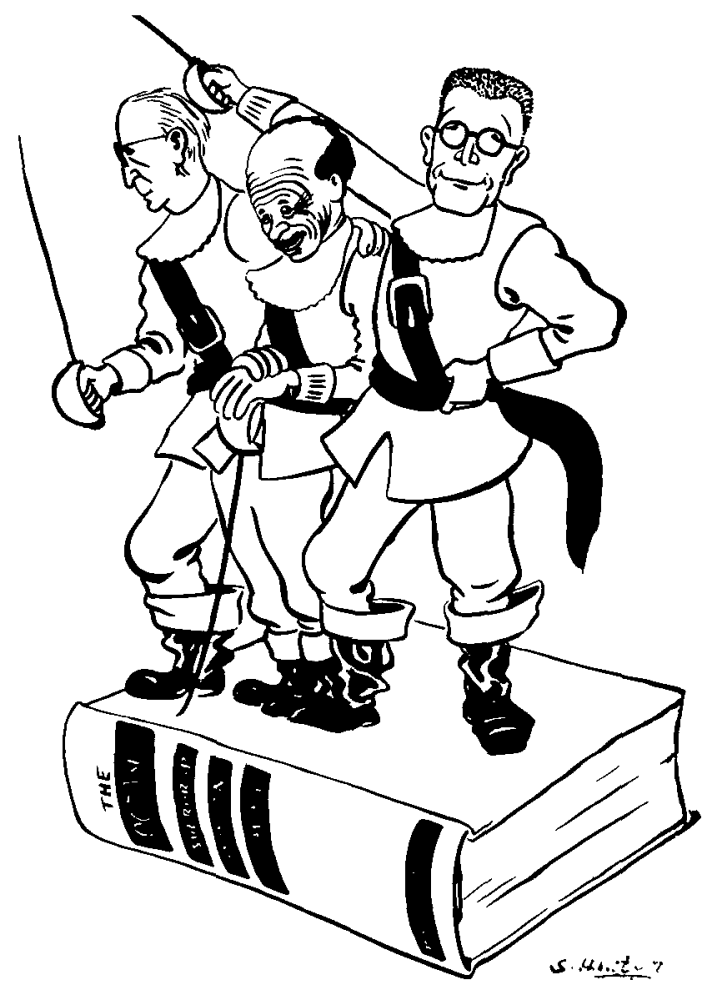

The Three Musketeers: Johnson, Sverdrup and Fleming (left to right).
So, what did The Oceans represent to geologists? When I arrived in oceanography as a postdoc from geology in 1959, The Oceans was the text in physical oceanography, and that was how geological oceanographers (whom I knew) used it. That is also how it is cited in Krumbein and Sloss's 1953 standard text, Stratigraphy and Sedimentation. I do not remember using The Oceans in graduate school geology courses, but the Fleming and Revelle chapter in Recent Marine Sediments is the most marked-up chapter in my copy of that book.

For the geological bookends of The Oceans, as for any pair of bookends, it is what they hold between them that is of greatest value. But were the book to be rewritten today, those two chapters would no doubt be more than bookends. The first would set the oceanographic stage with plate tectonics; the last would sum up the story of the ocean in paleoceanography. Such has been the change in the geology of the ocean in 50 years.

\section{References}

Shor, E.N., 1978: Scripps Institution of Oceanography: Probing the Oceans, 1936 to 1976. San Diego, Tofua, 502 pp. $\square$ 